\title{
Trends and factors associated with use of digital health technology among adults with serious psychological distress in the United States: A secondary data analysis of the National Health Interview Survey
}

\author{
Henry K. Onyeaka ${ }^{1,2,3}$, Isaac Acquah ${ }^{4,5}$, Joesph Firth ${ }^{6}$, Burhan A. Khan ${ }^{1,3}$, Philip Baiden ${ }^{7}$, Chioma Muoghalu ${ }^{8}$, Gibson \\ Anugwom ${ }^{9}$, John Torous ${ }^{1,10}$
}

\begin{abstract}
AFFILIATION
1 Department of Psychiatry, Harvard Medical School, Boston, United States

2 Department of Psychiatry, Massachusetts General Hospital, Boston, United States

3 Mclean Hospital, Department of Psychiatry, Boston, United States

4 Center for Outcomes Research, Houston Methodist, Houston, United States

5 Division of Cardiovascular Prevention and Wellness, Department of Cardiology, Houston Methodist, DeBakey Heart \& Vascular Center, Houston, United States

6 Faculty of Biology, Medicine and Health, Division of Psychology and Mental Health, School of Health Sciences, The University of Manchester, Manchester, United Kingdom

7 School of Social Work, The University of Texas at Arlington, Arlington,
\end{abstract}

United States

8 Duke University School of Medicine, Durham, United States

9 Houston Behavioral Healthcare Hospital, Houston, United States

10 Beth Israel Deaconess Medical Center, Boston, United States

\section{CORRESPONDENCE TO}

Henry K. Onyeaka. Department of Psychiatry, Harvard Medical School, Boston, Massachusetts 02215, United States. E-mail: honyeaka@mgh. harvard.edu

\section{KEYWORDS}

serious psychological distress, digital health, technology, disparities

Received: 7 December 2021, Revised: 16 January 2022,

Accepted: 17 January 2022

https://doi.org/10.18332/popmed/145913
$15.6 \%$ reported at least one technology-based interaction with the health system. During the 5-year period, the proportion of individuals with SPD who utilized any DHT to interact with the healthcare system doubled from $10.0 \%$ in 2013 to $21.3 \%$ in 2017 ( $\mathrm{p}<0.001)$. In multivariable models, several sociodemographic factors predicted DHT use.

CONCLUSIONS The use of DHT among individuals with SPD in the US increased between 2013 and 2017. However, sociodemographic disparities in DHT use among this population exist.

\section{INTRODUCTION}

Although evidence points towards increasing trends in access to outpatient mental health service use among adults in the United States ${ }^{1}$, a considerable proportion of individuals with serious psychological distress (SPD) still lack access to mental healthcare. SPD is an indicator of poor mental health that is severe enough to cause moderate-toserious impairment in social or occupational functioning and to require treatment ${ }^{2}$. Various studies have found that individuals with SPD continue to lag behind those with milder conditions (in terms of access to mental healthcare) and experience substantial unmet mental healthcare needs, despite being a high risk and extremely vulnerable group ${ }^{1,3,4}$.

Across the spectra of mental disorders, those with serious mental illness (SMI) such as schizophrenia, and other psychotic disorders warrant critical attention. Research shows people with SMI tend to lead unhealthy lifestyles typified by poor dietary habits, smoking, and physical inactivity with resultant worse physical outcomes and elevated mortality when compared to the general population $^{4,5}$. To further compound this, studies indicate that people with SMI have diminished access to mental health due to limited financial resources, lack of health insurance and problems with adherence to complex treatment regimens ${ }^{6}$. 
Emerging research has shown that DHT involving the use of smartphones, internet and other technologies for healthcare offers a cost-effective and feasible medium that may potentially improve access and continuity of mental health treatment services for people with mental disorders ${ }^{7}$. While prior studies have documented that individuals across all spectra of mental illness are reasonably digitally connected ${ }^{8,9}$, the sociodemographic determinants of digital engagement among those with SMI at the population level remain unexplored. Given the rapidly growing and evolving integration of technology in healthcare, a nuanced understanding of the utilization trends and factors associated with DHT use for obtaining healthcare among this group is crucial.

Accordingly, this study sought to address these research gaps by evaluating trends in DHT use as well as the sociodemographic determinants of DHT use among individuals with SPD.

\section{METHODS}

Data for this study were drawn from the National Health Interview Survey (NHIS), a nationally representative inperson survey conducted annually since 1957 by the National Center for Health Statistics. For this study, data were pooled from the 2013 to 2017 iterations of the NHIS. The survey utilizes a multistage area probability sample design, adjusting for non-response, and further allows for representativeness of the civilian, non-institutionalized population of the United States ${ }^{10}$. We assessed trends and sociodemographic factors associated with digital health technology use among adults (aged $\geq 18$ years) with SPD in the US from 2013-2017. SPD was assessed using the Kessler-6 (K6) non-specific distress scale. The K6 obtains information on the frequency of six psychological distress symptoms during the past 30 days. Each item is coded $0-4$ where 0 is 'none of the time' and 4 is 'all the time' (cumulative score ranging from 0 to 24). In this study, we used SPD as a proxy for SMI. This measure is highly validated and has demonstrated effectiveness as a screening tool for $\mathrm{SMI}^{2,11}$.

Consistent with prior studies ${ }^{12}$, SPD was defined as a score $\geq 13$ on the K6. We excluded individuals with missing information on use of digital health technology ( $n=1 ; 0.02 \%)$. Our analysis of a publicly available deidentified dataset for a national survey did not meet the federal definition of human subjects research, according to the NIH Human Subjects Research Decision Tool from the Harvard Medical School IRB.

Use of DHT was based on the response of 'yes' to any of the following in the past 12 months: using the Internet to fill a prescription, scheduling a medical appointment, and communicating with a healthcare provider. Other data collected in the NHIS and used for this study, informed by previous studies of DHT use ${ }^{13}$, were used and included the following: age, race/ethnicity, educational level, gender, family income, birth place, health insurance status, geographical region of the United States, and number of comorbidities.

\section{Statistical analysis}

Survey-specific descriptive characteristics were used to estimate the prevalence of DHT use, overall and by sociodemographic and clinical characteristics. Differences in participant characteristics by DHT use were assessed using Rao-Scott $\chi^{2}$. Continuous variables were summarized using mean \pm standard deviation, and categorical variables were summarized using proportions. We assessed the determinants of use of any DHT for health-related purposes using multivariable logistic regression and adjusted for all covariates. All analyses were performed using Stata version 16.0 (StataCorp LLC, College Station, Texas). For all analyses, a two-tailed alpha level of 0.05 was considered statistically significant. We accounted for the complex survey design of the NHIS to ensure that our results were generalizable to the US population. Variance estimation and person-level sample weights (representing the inverse probability of a person being selected) were obtained from the Integrated Public Use Microdata Series website ${ }^{14}$.

\section{RESULTS}

Our study population included 6110 adults with SPD from 2013-2017, representing 8.2 million adults annually; mean age of $46.7 \pm 17.4$ years; $60.9 \%$ were women, $65.4 \%$ were non-Hispanic Whites and $13.2 \%$ were aged $\geq 65$ years. On average, $15.6 \%$ reported at least 1 technology-based interaction with the healthcare system; 7.6\% (95\% CI: 6.78.5) filled a prescription on the Internet, 8.2\% (95\% CI: 7.39.3) scheduled a medical appointment on the Internet, and 9.4\% (95\% CI: 8.3-10.6) communicated with a healthcare provider by e-mail between 2013 and 2017.

Individuals with SPD who reported using any DHT to interact with the healthcare system were more likely to be younger ( $93.7 \%$ were aged $<64$ years), women $(66.0 \%)$, nonHispanic White (70.9\%), born in the US (91.4\%), have high income (29.2\%), and have some college or higher education (72.1\%) compared with those who did not report any use of DHT. However, they were less likely to report being noninsured (12.4\%) (Table 1).

The proportion of individuals with SPD who utilized at least DHT to interact with the healthcare system increased significantly from $10.0 \%$ in 2013 to $21.3 \%$ in 2017 ( $p<0.001$ ) (Figure 1). Within the same period, the proportion who filled a prescription on the Internet increased from $5.3 \%$ to $10.3 \%$ $(p=0.006)$, those who scheduled a medical appointment on the Internet increased from $4.8 \%$ to $11.4 \%(\mathrm{p}<0.001)$, and those who communicated with a healthcare provider by e-mail increased non-significantly from $6.4 \%$ to $12.1 \%$ $(p=0.07)$ (Figure 1).

In multivariable analysis, younger age, female sex, higher education level, high income, having public health insurance, belonging to the western United States regions, and having at least one chronic health condition were significant predictors of using DHT (Table 2). 
Table 1. General characteristics of adults with SPD, from the National Health Interview Survey, 2013-2017

\begin{tabular}{|c|c|c|c|c|}
\hline Characteristics & $\begin{array}{c}\text { Total } \\
\text { n (weighted \%) }\end{array}$ & $\begin{array}{l}\text { Not used at all } \\
\text { n (weighted \%) }\end{array}$ & $\begin{array}{c}\text { Used any } \\
\text { n (weighted \%) }\end{array}$ & $\mathbf{p}$ \\
\hline Sample, $\mathrm{n}$ & 6110 & 5223 & 887 & \\
\hline Weighted sample & 8201810 & 6918746 (84.3) & 1283064 (15.6) & \\
\hline Age (years), mean \pm SD & $46.7 \pm 17.1$ & $47.4 \pm 17.4$ & $42.6 \pm 14.7$ & \\
\hline Age (years) & & & & $<0.001$ \\
\hline$\geq 65$ & 993 (13.2) & 919 (14.5) & $74(6.3)$ & \\
\hline $40-64$ & $3332(52.2)$ & $2855(52.5)$ & $477(50.8)$ & \\
\hline $18-39$ & $1785(34.6)$ & $1449(33.1)$ & $336(42.9)$ & \\
\hline Sex & & & & 0.014 \\
\hline Men & $2202(39.1)$ & $1921(40.0)$ & $281(34.0)$ & \\
\hline Women & 3908 (60.9) & $3302(60.0)$ & $606(66.0)$ & \\
\hline Race/ethnicity & & & & $<0.001$ \\
\hline Non-Hispanic White & $3863(65.4)$ & $3236(62.3)$ & $627(70.9)$ & \\
\hline Non-Hispanic Black & 847 (12.5) & 736 (12.7) & $111(11.9)$ & \\
\hline Hispanic & $1094(17.1)$ & 997 (18.3) & $97(10.6)$ & \\
\hline Non-Hispanic Other & $306(5.0)$ & $254(4.7)$ & $52(6.6)$ & \\
\hline Birth place & & & & 0.001 \\
\hline Outside US & 822 (13.5) & $746(14.4)$ & $76(8.6)$ & \\
\hline US & $5285(86.5)$ & $4475(85.6)$ & $810(91.4)$ & \\
\hline Education level & & & & $<0.001$ \\
\hline HS/GED or less than HS & 3351 & $3123(60.9)$ & $228(27.9)$ & \\
\hline Some college or higher & 2725 & $2069(39.1)$ & $656(72.1)$ & \\
\hline Family income & & & & $<0.001$ \\
\hline Lowest & $2883(41.8)$ & $2608(44.7)$ & $275(26.4)$ & \\
\hline Low & 1117 (19.8) & $981(20.7)$ & $136(14.8)$ & \\
\hline Middle & $1166(23.4)$ & $939(22.3)$ & $227(29.5)$ & \\
\hline High & $660(15.0)$ & $444(12.3)$ & $216(29.2)$ & \\
\hline Insurance status & & & & $<0.001$ \\
\hline Uninsured & $1054(18.4)$ & 956 (19.5) & $98(12.4)$ & \\
\hline Public & 3535 (53.9) & $3125(56.0)$ & $410(43.1)$ & \\
\hline Private & $1427(27.7)$ & $1062(24.6)$ & $365(44.5)$ & \\
\hline Region & & & & 0.002 \\
\hline Northeast & $984(15.0)$ & $856(15.1)$ & $128(14.0)$ & \\
\hline Midwest & $1230(22.7)$ & $1030(22.5)$ & $200(23.6)$ & \\
\hline South & $2300(38.7)$ & 2031 (39.9) & $269(32.3)$ & \\
\hline West & $1596(23.7)$ & $1306(22.5)$ & $290(30.1)$ & \\
\hline Comorbidities & & & & 0.16 \\
\hline 0 & 1851 (33.9) & 1595 (34.3) & $256(31.4)$ & \\
\hline 1 & $1861(30.3)$ & 1568 (29.7) & 293 (33.9) & \\
\hline$\geq 2$ & 2398 (35.8) & $2060(36.0)$ & 338 (34.8) & \\
\hline
\end{tabular}

GED: General Equivalency Diploma. HS: high school. SD: standard deviation. P values were calculated using Rao-Scott $\chi^{2}$. Family income (based on the percentage of family income relative to the federal poverty limit from the US Census Bureau, categorized as high income [ $\geq 400 \%]$, middle income [200 to $<400 \%$ ], low income [125 to $<200 \%]$, and lowest income [<125\%]). Comorbidities included were COPD, asthma, cancer, arthritis, ulcer, liver disease and kidney disease. 
Figure 1. Trends in proportion of individuals with SPD reporting use of DHT from 2013-2017

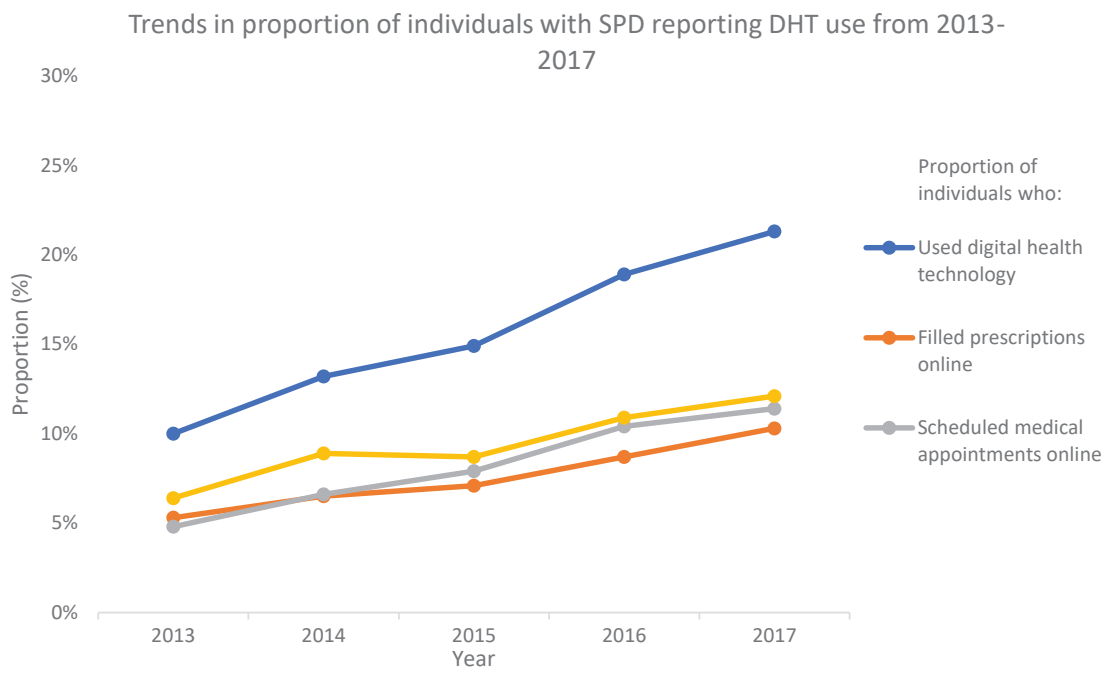

Table 2. Determinants of use of digital health technology to interact with the healthcare system among adults with serious psychological distress, from the National Health Interview Survey, 2013-2017

\begin{tabular}{|c|c|c|c|c|}
\hline \multirow[t]{2}{*}{ Variables } & \multicolumn{4}{|c|}{ Use of digital health technology } \\
\hline & $O R^{a}(95 \% C I)$ & $\mathbf{p}$ & $\mathrm{AOR}^{\mathrm{b}}(95 \% \mathrm{CI})$ & $\mathbf{p}$ \\
\hline \multicolumn{5}{|l|}{ Age (years) } \\
\hline$\geq 65$ (Ref.) & 1 & & 1 & \\
\hline $40-64$ & $2.21(1.62-3.03)$ & $<0.001$ & $2.36(1.66-3.35)$ & $<0.001$ \\
\hline $18-39$ & $2.97(2.13-4.15)$ & $<0.001$ & $3.35(2.23-5.03)$ & $<0.001$ \\
\hline \multicolumn{5}{|l|}{ Sex } \\
\hline Male (Ref.) & 1 & & 1 & \\
\hline Female & $1.29(1.05-1.58)$ & 0.014 & $1.28(1.02-1.60)$ & 0.034 \\
\hline \multicolumn{5}{|l|}{ Race/ethnicity } \\
\hline Non-Hispanic White (Ref.) & 1 & & 1 & \\
\hline Non-Hispanic Black & $0.85(0.64-1.13)$ & 0.27 & $1.08(0.79-1.49)$ & 0.62 \\
\hline Hispanic & $0.52(0.38-0.71)$ & $<0.001$ & $0.71(0.47-1.07)$ & 0.10 \\
\hline Non-Hispanic Other & $1.29(0.81-2.03)$ & 0.28 & $1.29(0.76-2.20)$ & 0.94 \\
\hline \multicolumn{5}{|l|}{ Birth place } \\
\hline Outside US (Ref.) & 1 & & 1 & \\
\hline US & $1.79(1.27-2.51)$ & 0.001 & $1.27(0.84-1.93)$ & 0.26 \\
\hline \multicolumn{5}{|l|}{ Education level } \\
\hline HS/GED or less than HS (Ref.) & 1 & & 1 & \\
\hline Some college or higher & $4.01(3.26-4.94)$ & $<0.001$ & $2.92(2.33-3.64)$ & $<0.001$ \\
\hline \multicolumn{5}{|l|}{ Family income } \\
\hline Lowest (Ref.) & 1 & & 1 & \\
\hline Low & $1.21(0.91-1.62)$ & 0.19 & $1.16(0.84-1.58)$ & 0.35 \\
\hline Middle & $2.24(1.71-2.95)$ & $<0.001$ & $1.84(1.33-2.53)$ & $<0.001$ \\
\hline High & $4.01(2.98-5.38)$ & $<0.001$ & $2.79(1.96-3.97)$ & $<0.001$ \\
\hline
\end{tabular}


Table 2. Continued

\begin{tabular}{|c|c|c|c|c|}
\hline \multirow[t]{2}{*}{ Variables } & \multicolumn{4}{|c|}{ Use of digital health technology } \\
\hline & $\mathrm{OR}^{\mathrm{a}}(95 \% \mathrm{CI})$ & p & $\mathrm{AOR}^{\mathrm{b}}(95 \% \mathrm{CI})$ & $\mathbf{p}$ \\
\hline \multicolumn{5}{|l|}{ Insurance status } \\
\hline Uninsured (Ref.) & 1 & & 1 & \\
\hline Public & $2.84(2.04-3.96)$ & $<0.001$ & $1.58(1.08-2.29)$ & 0.017 \\
\hline Private & $1.21(0.88-1.67)$ & 0.25 & $1.39(0.96-2.02)$ & 0.08 \\
\hline \multicolumn{5}{|l|}{ Region } \\
\hline Northeast (Ref.) & 1 & & 1 & \\
\hline Midwest & $1.13(0.80-1.62)$ & 0.48 & $1.14(0.77-1.69)$ & 0.51 \\
\hline South & $0.88(0.63-1.22)$ & 0.63 & $1.04(0.72-1.51)$ & 0.82 \\
\hline West & $1.45(1.02-2.04)$ & 1.02 & $1.51(1.03-2.21)$ & 0.033 \\
\hline \multicolumn{5}{|l|}{ Comorbidities } \\
\hline 0 (Ref.) & 1 & & 1 & \\
\hline 1 & $1.25(0.99-1.58)$ & 0.06 & $1.39(1.06-1.84)$ & 0.018 \\
\hline$\geq 2$ & $1.06(0.85-1.32)$ & 0.62 & $1.62(1.23-2.14)$ & 0.001 \\
\hline
\end{tabular}

AOR: adjusted odds ratio. GED: General Equivalency Diploma. HS:High School.aUnadjusted model. bModel adjusted for all variables in table.

\section{DISCUSSION}

In this nationally representative study, we evaluated the trends and sociodemographic determinants of using digital technology to interact with the healthcare system among those with mental disorders. We found that the use of DHT among individuals with SPD doubled from 10.0\% in 2013 to $21.3 \%$ in 2017, indicating that this population is becoming increasingly digitally connected. Despite the encouraging evidence showing increasing trends in digital health interactions from our study, findings reveal that some adults with SPD may be digitally disconnected.

Findings indicate that among people with SPD, older age, male sex, lower education level, and lower income, were associated with lower odds of using DHT to interact with the healthcare system. These findings are consistent with previous research which suggests that trends in DHT use across the general population is increasing but disparities in DHT engagement still exist, which could potentially exacerbate health disparities ${ }^{13,15}$. The finding that individuals with higher education level and high-income high SES background are more likely to use DHT matches observations from past studies ${ }^{16}$. That notwithstanding, cost, lack of access to Internet, and lack of awareness have been cited as some of the reasons accounting for disparities in the use of DHT among individuals with low SES ${ }^{17,18}$.

Given the rapid transition to technology-supported healthcare services to combat the ongoing SARS COVID-19 pandemic ${ }^{19}$, identifying patient groups among those with mental illness that lack digital access is crucial from a public health perspective. These results, indicating disproportionately lower rates of digital health interactions among vulnerable sociodemographic groups of people with SPD, will guide health systems, stakeholders and policy players to develop targeted public health strategies to address these critical gaps. Additionally, since low socioeconomic status is correlated with poor mental health outcomes, we theorize that DHT use may be a measure for SES and could help identify high risk and vulnerable groups among those with SPD.

\section{Strengths and limitations}

One major strength of this study is the use of the NHIS which is a nationally representative survey and enables generalizability of our findings to the non-institutionalized US population. However, the findings of our study should be interpreted with the following limitations in mind. First, data on DHT use were self-reported and subject to recall bias. Second, the cross-sectional nature of the study precludes any causal inferences. Lastly, while we found increased trends in DHT use over the 5-year period, the NHIS data did not provide any information on digital device ownership, access to the Internet, and frequency of DHT use - all of which may explain the growing trend in DHT engagement and inform future interventions.

\section{CONCLUSIONS}

This study observed an increasing trend in the utilization of DHT among adults with SPD in the US between 2013 and 2017. However, a subset of people with SPD may not be digitally connected. Therefore, future studies that focus 
on investment in technology as well as strategies to reduce digital access disparities in adults with SPD are essential.

\section{REFERENCES}

1. Olfson M, Wang S, Wall M, Marcus SC, Blanco C. Trends in Serious Psychological Distress and Outpatient Mental Health Care of US Adults. JAMA Psychiatry. 2019;76(2):152-161. doi:10.1001/jamapsychiatry.2018.3550

2. Swartz JA, Jantz I. Association Between Nonspecific Severe Psychological Distress as an Indicator of Serious Mental Illness and Increasing Levels of Medical Multimorbidity. Am J Public Health. 2014;104(12):2350-2358. doi:10.2105/AJPH.2014.302165

3. Muhuri PK. Serious Psychological Distress and Mortality among Adults in the U.S. Household Population: Highlights. In: The CBHSQ Report. Substance Abuse and Mental Health Services Administration; 2014. Accessed January 16, 2022. http://www.ncbi.nlm.nih.gov/books/NBK385058/

4. Pearson WS, Dhingra SS, Strine TW, Liang YW, Berry JT, Mokdad AH. Relationships between serious psychological distress and the use of health services in the United States: findings from the Behavioral Risk Factor Surveillance System. Int J Public Health. 2009;54(suppl 1):23-29. doi:10.1007/s00038-009-0003-4

5. Viron MJ, Stern TA. The Impact of Serious Mental Illness on Health and Healthcare. Psychosomatics. 2010;51(6):458465. doi:10.1176/appi.psy.51.6.458

6. Lawrence D, Kisely S. Inequalities in healthcare provision for people with severe mental illness. J Psychopharmacol. 2010;24(4 Suppl):61-68. doi:10.1177/1359786810382058

7. Onyeaka HK, Wisniewski H, Henson P, Torous J. Understanding the evolving preferences for use of health information technology among adults with self reported anxiety and depression in the U.S. J BehavCognTher. 2020;30(1):49-56. doi:10.1016/j.jbct.2020.03.017

8. Naslund JA, Aschbrenner KA, Bartels SJ. How People with Serious Mental Illness Use Smartphones, Mobile Apps, and Social Media. PsychiatrRehabil J. 2016;39(4):364-367. doi:10.1037/prj0000207

9. Torous J, Chan SR, Yee-Marie Tan S, et al. Patient Smartphone Ownership and Interest in Mobile Apps to Monitor Symptoms of Mental Health Conditions: A Survey in Four Geographically Distinct Psychiatric Clinics. JMIR Ment Health. 2014;1(1):e5. doi:10.2196/mental.4004

10. National Health Interview Survey: 1997-2018. National Center for Health Statistics. Updated October 20, 2020. Accessed January 16, 2022. https://www.cdc.gov/nchs/ nhis/1997-2018.htm

11. Kessler RC, Barker PR, Colpe LJ, et al. Screening for Serious Mental Illness in the General Population. Arch Gen Psychiatry. 2003;60(2):184-189. doi:10.1001/archpsyc.60.2.184

12. Weissman J, Pratt LA, Miller EA, Parker JD. Serious Psychological Distress Among Adults: United States, 20092013. NCHS Data Brief, No. 203. U.S. Department of Health and Human Services, Centers for Disease Control and Prevention, National Center for Health Statistics. May 2015. Accessed January 16, 2022. https://www.cdc.gov/nchs/ data/databriefs/db203.pdf

13. Mahajan S, Lu Y, Spatz ES, Nasir K, Krumholz HM. Trends and Predictors of Use of Digital Health Technology in the United States. Am J Med. 2021;134(1):129-134. doi:10.1016/j.amjmed.2020.06.033

14. Blewett LA, Drew JAR, Griffin R, King ML, Williams KCW. IPUMS Health Surveys: National Health Interview Survey, Version 6.3 [dataset]. IPUMS; 2018. doi:10.18128/D070.V6.3

15. Nwokeji U, Spaulding EM, Shan R, et al. Health Information Technology Use Among Persons With Self-reported Atherosclerotic Cardiovascular Disease: Analysis of the 2011-2018 National Health Interview Survey. J Med Internet Res. 2021;23(8):e23765. doi:10.2196/23765

16. Onyeaka H, Firth J, Kessler RC, Lovell K, Torous J. Use of smartphones, mobile apps and wearables for health promotion by people with anxiety or depression: An analysis of a nationally representative survey data. Psychiatry Res. 2021;304:114120. doi:10.1016/j.psychres.2021.114120

17. Kim H, Mahmood A, Goldsmith JV, Chang H, Kedia S, Chang CF. Access to Broadband Internet and its Utilization for Health Information Seeking and Health Communication among Informal Caregivers in the United States. J Med Syst. 2021;45(2):24. doi:10.1007/s10916-021-01708-9

18. Reglitz M, Rudnick A. Internet access as a right for realizing the human right to adequate mental (and other) health care. Int J Ment Health. 2020;49(1):97-103. doi:10.1080/00207411.2020.1727019

19. Torous J, Jän Myrick K, Rauseo-Ricupero N, Firth J. Digital Mental Health and COVID-19: Using Technology Today to Accelerate the Curve on Access and Quality Tomorrow. JMIR Ment Health. 2020;7(3):e18848. doi:10.2196/18848 


\section{CONFLICTS OF INTEREST}

The authors have each completed and submitted an ICMJE form for disclosure of potential conflicts of interest. The authors declare that they have no competing interests, financial or otherwise, related to the current work. JF is supported by a University of Manchester Presidential Fellowship (P123958) and a UK Research and Innovation Future Leaders Fellowship (MR/T021780/1) and has received honoraria/consultancy fees from Atheneum, ParachuteBH and Nirakara, independent of this work. JT is supported by a research fellowship from the American Psychiatric Association Foundation and the American Psychiatric Association. JT also receives support from Otsuka unrelated to this work.

\section{ETHICAL APPROVAL AND INFORMED CONSENT}

Ethical approval and informed consent were not required for this study which used data from the National Health Interview Survey (NHIS), a nationally representative in-person survey.

\section{DATA AVAILABILITY}

The data supporting this research are available from the authors on reasonable request.

\section{PROVENANCE AND PEER REVIEW}

Not commissioned; externally peer reviewed.

FUNDING

There was no source of funding for this research. 